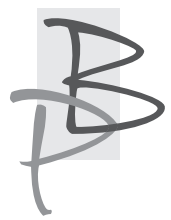

\title{
Memories of Mogadishu: Reconstructing post-conflict societies through memory and storytelling
}

Abstract: For many members of the Somali diaspora, the fear of fading memories places a sense of urgency on them to keep these stories of their homeland alive. The great African novelist Ben Okri once said, "to poison a nation, poison its stories". Stories have the ability to harm or heal societies. Oftentimes, it is simply exclusion from the main narrative that can greatly harm or marginalize a group of people. This paper examines the use of memory in the reconstruction of a once cosmopolitan city by the Somali diaspora around the world through the Memories of Mogadishu initiative. The film by the same title is a short documentary made by the author, in which she interviews nine members of the Somali diaspora currently residing in Canada. Ultimately, this project and this paper reveal the realities of how post-conflict societies, and individuals within them, reconstruct and reconcile their memories, in this case of their former home of Mogadishu, Somalia. This paper analyses the nine interviews and is divided into the follow-

\footnotetext{
Asha Siad is a Somali-Canadian filmmaker. Her recent credits include the Amnesty International Canada Media Award winner Living at the Border, which is an interactive documentary that explores the experiences of African asylum-seekers in Italy. Asha's latest film, Memories of Mogadishu, reveals the realities of how post-conflict societies reconstruct and reconcile their memories of Mogadishu.
} 
ing four sections: "Memories of Mogadishu before the Civil War", "Civil War and Leaving Mogadishu”, "Identity Revision, Memory, and Routinization", and "Losing and Rebuilding Memories of Mogadishu (and Themselves)".

Key words: Mogadishu, Somalia, refugees, migration, narratives, memory processes, stories. 

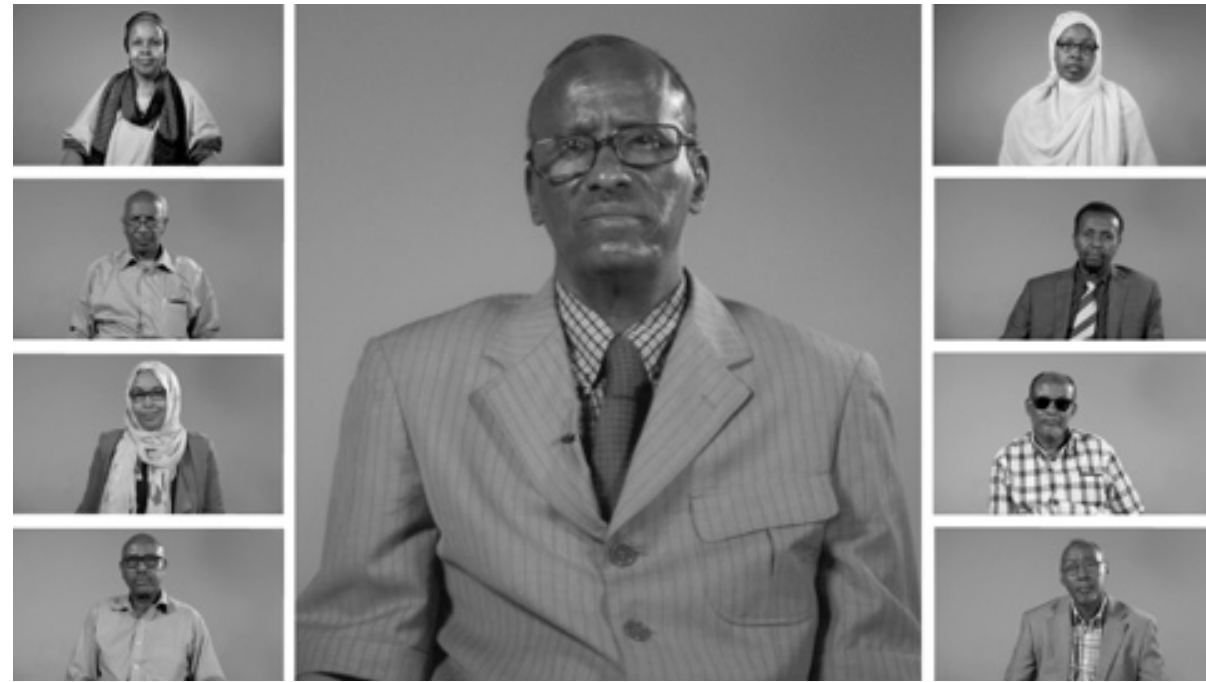

IMAGE 1. Portraits of individuals who were interviewed for the film Memories of Mogadishu.

Left, top to bottom: Fowsia, Abdirahman, Ahmed G, Omar.

Centre: Hersi. Right, top to bottom: Canab, Ahmed A, Hamdi, Dahir.

"To me, memory is something that we live in all the time, live with, but the memory of a place. It fascinates me just how intertwined your thoughts, your dreams, your psyche is to a place that you might not have been for a long time."1

\section{Introduction}

As written in Shirin Ramzanali Fazel's book Far from Mogadishu, "Mogadishu is a city that exists in the stories of its inhabitants, now displaced in various parts of the world, and only thanks to their memories can it be reconstructed"2. Despite the mainstream media portrayal of Somalia as a place of violence,

1 A. Siad, Voice of Fowsia, Memories of Mogadishu, 2020, https://www.youtube.com/ watch? $=$ mhjV82gQ0Zg\&t.

2 S. Ramzanali Fazel, Far From Mogadishu, Datanews: 1994. 
destitution and death, for those who are part of Shirin's generation, their homeland is far from those news media images. They have countless stories, from long days spent at Lido Beach enjoying ice lollies, to catching a movie in one of the city's many open-air theatres. Mogadishu is preserved in their minds and in their stories.

The Memories of Mogadishu initiative is based in Canada and is one that I have been leading for several years. It is a multimedia project which includes a short documentary film, which I directed and conducted the interviews for the film. The overall initiative offers an intimate portrait and unprecedented glimpse into the lives (past and present) of nine people who experienced displacement related to almost two decades of political instability and conflict. Through multimedia storytelling, the project combines archival footage with personal interviews of members of the global Somali diaspora, with the goal of documenting their collective memory of the pre-civil war city. Furthermore, the initiative reveals the realities of how post-conflict societies reconstruct and reconcile their memories of a once cosmopolitan city.

While memory can play an important role in healing and creating a sense of belonging for individuals, it can also be a source of pain. In an interview with Memories of Mogadishu, Professor and leading linguist Cabdalla Umar Mansur from Rome, Italy, says that "I kept thinking it would end this year, but the next year, and eventually it's become 27 years of me being in Italy." In Birmingham, United Kingdom, writer Shirin Ramzanali Fazel shares that writing memories allowed her to heal: "I left Mogadishu in 1971, and I started writing the book in $1991 \ldots$ it was almost 20 years, and for me it was not difficult to remember everything suddenly... in a way, it is like you are telling yourself you don't want to lose these memories... you want to see them written, in a way you keep them." Across the globe in Ottawa, Canada, Fowsia Abdulkadir, a researcher and human rights activist, talks about the moment the war broke out: "In December 1990 the war broke, the first thing that hit me at a very sort of visceral level was ok I don't have the option of going home once a year anymore... that was taken away... it felt like someone kind of removing the rug under your feet... you have no option now, you cannot go back because it's not safe to go back"3. The memories of these three members of the Somali

3 A. Siad, Voice of Fowsia, op cit. 
diaspora, which appear to be worlds away, capture the intergenerational experiences and sense of loss faced by some of those who have been most impacted by conflict. It also shifts the narrative by putting the individuals at the centre of their stories as it relates to the past.

The recent Memories of Mogadishu documentary film takes place inside of a photo studio. This short film offers an intimate portrait and unprecedented glimpse into the lives of those who have been forcibly displaced by conflict. It can be considered a form of mediated memory work ${ }^{4}$, given that the film offers a representation of the past that is transmitted through a form of media, while also affecting the construction of both personal and collective memory. Both the film and this paper strive to address the following question: How does the Somali diaspora remember or reimagine the once cosmopolitan city of Mogadishu? To do so, interviews were conducted with nine individuals currently residing in Canada. The transcripts of their individual life narratives were analysed to identify what themes emerged. Within each of these themes, specific content was analysed to further understand what is remembered and how remembering takes places.

This paper is divided into the following four sections, which present the results related to the research question stated above: "Memories of Mogadishu before the Civil War", "Civil War and Leaving Mogadishu", "Identity Revision, Memory, and Routinization", and "Losing and Rebuilding Memories of Mogadishu (and Themselves)". This sequence of thematic analysis also follows both the flow and narrative of the film Memories of Mogadishu, as well as the life story trajectories described by the nine interviewees.

\section{Memories of Mogadishu before the Civil War}

Individuals interviewed for the film Memories of Mogadishu described their experiences and thoughts about Mogadishu as it was before the war. Fowsia, a human rights activist and researcher who left Mogadishu 40 years ago, brings the viewer into her perspective as she describes: "When I close my eyes Mogadishu is that beautiful, white villas, and the Indian ocean, and every Fri-

4 C. Lohmeier and C. Pentzold, Making mediated memory work: Cuban-Americans, Miami media and the doings of diaspora memories, "Media, Culture \& Society", 36(6): 2014, pp. 776-789. 
day going to the Indian ocean and just listening... There is a special noise that comes from the ocean." 5 Abdirahman, a former tech and production manager at the state printing agency who left Somalia 30 years ago, echoes these sentiments, as he describes his reflections and experiences of Mogadishu:

Honestly, it was a city known as the pearl of the Indian Ocean because it was a beautiful city, very colourful, attracting all kinds of people. The infrastructure was very vintage. That could have been a heritage site today. A place in the history books of Africa like Zanzibar and many others ${ }^{6}$.

As a former government official who left Mogadishu 27 years ago, Dahir describes the broader society and functioning in Somalia from his perspective: "My best memories... I remember my country was at a very good place, grasping development, education was at an all time high, the economy was developing. Back then, the Somali Shilling compared to USE, \$1 was 3 Somali Shillings. Everyone was living significantly fine. It was good." Ahmed G, a former pilot for Somalia Airlines who left 28 years ago, shares a perspective specific to the centrality of Mogadishu: "Mogadishu was the centre of the whole Somalia, where if you are from North, South, anywhere where you come and present your talent of your music of your entertainment and that was one thing I will always remember."

Reflecting specifically on Mogadishu, Dr. Hamdi Mohamed, a social historian and author with a $\mathrm{PhD}$, who left Somalia 30 years ago, states that it "was a very serene, beautiful, cosmopolitan city. With each neighbourhood having its own culture, its own dynamic, its own community." ${ }^{9}$ Regarding interactions between people, Canab was a businesswoman in Somalia who left 26 years

5 A. Siad, Voice of Fowsia, op. cit.

6 A. Siad, Voice of Abdirahman, Memories of Mogadishu, 2020, https://www.youtube.com/ watch? $=$ mhjV82gQ0Zg\&t.

7 Idem, Voice of Dahir, Memories of Mogadishu, 2020, https://www.youtube.com/ watch? $\mathrm{v}=$ mhjV82gQ0Zg\&t.

8 Idem, Voice of Ahmed Ali, Memories of Mogadishu, 2020, https://www.youtube.com/ watch? $v=$ mhjV82gQ0Zg\&t.

9 Idem, Voice of Canab, Memories of Mogadishu, 2020, https://www.youtube.com/ watch? $=$ mhjV82gQ0Zg\&t 
ago. She describes the Somalia of her memory as "a country where nobody will ask who you are or where you come from. The neighbours were like your mother and father, who would take care of us if we were outside". Ahmed A, a former businessman who left Somalia 30 years ago, brings these themes together with the following statement:

Somalia got its independence in 1960. The memories I can recall now is that a country that existed for 17 years, that declared its own independence in Africa, and reached self-sufficiency. And if you finish university or high school you graduate debt-free and nothing is demanded from you. When you finish university, a job is offered to you, provided to you. That is the best memory I have and will never forget. Because when you go to other countries, peaceful, lavish countries, you see how their children are overwhelmed with university and life balance. And it is not free. So in my opinion Somalia was the most developed country that I could see. Other African countries reached out to us [Somalia] to help with education. That was Africa! 10

Taken together, the quotes presented in this section reveal an idealized remembering of Mogadishu. They represent a city that was not troubled by war or conflict, and instead represent a city that was a regional leader in many ways, one of great potential, and one in which the interviewees were living a good life in a city of which they were proud.

\section{Civil War and Leaving Mogadishu}

War and migration relate to a diversity of challenges at several different points in time. Following the idyllic descriptions and memories of Mogadishu before the war that were brought forward by those who were interviewed, the realities of civil war and its repercussions began to settle in. Canab observes that:

The country seemed to be giving birth to a war and had this smell of war. We did not have any experience of war. The first time was in primary/intermediate school that was in my neighborhood, a huge missile passed over us that hit a place 
that was relatively 200 metres away from us, that was not that far away from us. At that time we decided to get out of Mogadishu11.

Dr. Hersi Mohamed Eyow, a medical doctor who left Somalia 26 years ago and was practicing in Mogadishu during the conflict, shares his experience that reveals the challenges of the particular circumstances they were under:

Oh, it was a difficult time because at that time when people are coming to our clinic in SOS, laboratories were not functioning, blood transfusion bank was not functioning, even electricity was not functioning. So we used to treat the patient with blood transfusions. Once we know the blood group of the person, we used to give the blood transfusion through one person to another person because you do not have those bottles that you can sustain the blood so it was very difficult ${ }^{12}$.

In describing daily life and how the war affected being able to do his work, Abdirahman adds that:

The conditions we were working under were very scary. Sometimes, the last day before the war started, I still remember, the minister called me and he said, "are you going to produce the newspaper today"? I said, "I cannot come because my region where my house is located has been taken over by the battle so I cannot even move to one metre close to the print shop."13

A difference is noted between the physical objects, infrastructure and architecture of Mogadishu, as compared to the people and family in Mogadishu. Dr. Hamdi Mohamed recounts that:

At the time, we were absolutely not concerned of anything breaking. Building can be rebuilt, but family members were lost. So I don't remember consciously

11 Idem, Voice of Canab, op. cit.

12 Idem, Voice of Hersi, Memories of Mogadishu, 2020, https://www.youtube.com/ watch? $\mathrm{v}=\mathrm{mhjV} 82 \mathrm{gQ0Zg \& t}$.

13 Idem, Voice of Abdirahman, op. cit. 
thinking about Mogadishu buildings or places where we grew up or homes or any of that. Because first things first if you will...our priority was finding out if our family was alive or not ${ }^{14}$.

Similarly, Fowsia describes the stories that she was hearing from family regarding what was going on in Mogadishu. At the time when the conflict erupted, she was not in Somalia:

It was very vivid the way they were telling the stories, my cousins, my dad was still there. The way they were talking about how they got out actually gave me dreams of nightmares and seeing, because I know the streets they were describing, I know where they lived in Mogadishu, I know when they talk about leaving the Bakarii area going all the way to Medina, which is the south end of Mogadishu, I know what that route entails and then they will tell you how many roadblocks and what intersections they had to negotiate to get through. So I started dreaming about that, which is weird. I started seeing because you know the place, the people, so I would see in my dreams loads of buses of people, men with guns, roadblocks, what was being described is what was I seeing in my dreams, so sad. It makes me really sad ${ }^{15}$.

Dahir describes how he went from being a deputy director leading a major project, to being a refugee fleeing to Kenya by foot:

My goodness! The war left us with an enduring negative impact. I was one of the people who sought refuge in Kenya. Just imagine that you are a knowledgeable person, I was a deputy director and led a project on the decentralization of education funded by the World Bank. I worked in the educational sector of the federal government. On that day, the war began in Mogadishu. The director and I planned to go to New York to meet with the World Bank to discuss the project's funding. So, it had an impact on us. I became a refugee, so just imagine, fleeing Mogadishu and you go to Kenya by foot, and being in a car that is getting stuck

14 Idem, Voice of Hamdi, Memories of Mogadishu, 2020, https://www.youtube.com/ watch? $=$ mhjV82gQ0Zg\&t.

15 Idem, Voice of Fowsia, op. cit. 
in places. That was a rough journey. Honestly, you cannot visualize how much Somali people have suffered and the impact it had on them ${ }^{16}$.

Describing the physical destruction and sense of loss, Abdirahman reflects that "we were the heart of the economy of the country, so there is a lot of memories. There is a lot of anger in me when I saw what we have built for so many years has been destroyed in just a couple of days. It took 40 years to produce and build all that technology and machinery." 17 Ahmed A summarizes these thoughts with the following statement: "For me, I saw it as the shattered paradise. It was shattered by its own people, in my perspective. There was no foreign army that invaded Somalia. We destroyed it with our own hands." 18

The quotes presented in this section demonstrate how the interviewees remember the emergence of the conflict and reflect on loss. These memories are especially poignant and meaningful relative to the previous section, in which Mogadishu is recalled positively, as a regional leader, and full of potential. Interestingly, the memories presented in this section refer to both the loss experienced by Mogadishu as a city and the loss experienced by the individuals. They lost the opportunity to live in Mogadishu as a result of the conflict, and they lost the life that they had been cultivating for themselves.

\section{Identity Revision, Memory, and Routinization}

It is important at this point in the analysis to integrate a reflection of identity revision, memory, and routinization as related to trauma. It is at this point in the film Memories of Mogadishu, that the nine interviewees describe a "before" and "after" moment in their lives. These can be interpreted as before/after trauma, before/after migration, before/after a sense of "normality", among others. It is understood that the trajectory they had been on before the outbreak of the civil war was ruptured in a traumatic way that affected them individually and collectively, in a way that was directly related to their Somali identity and to Somalia itself. They were put in a position of needing to leave Somalia,

16 Idem, Voice of Dahir, op. cit.

17 Idem, Voice of Abdirahman, op. cit.

18 Idem, Voice of Ahmed Ali, op. cit. 
thereby being uprooted and needing to reconfigure themselves and their identities as they sought safety outside of their home country.

"Experiencing trauma" can be understood as a sociological process that defines a painful injury to the collectivity, establishes the victim, attributes responsibility, and distributes both ideal and material consequences. Insofar as traumas are so experienced, and thus imagined and represented, the collective identity can become significantly revised. This identity revision suggests that there will be a searching and re-remembering of the collective past, for memory is not only social and fluid but deeply connected to the contemporary sense of the self. Identities are continuously constructed and secured not only by facing the present and future, but also by reconstructing the collectivity's earlier life ${ }^{19}$.

The process of migration involves the loss of social networks, isolation and alienation. Dinesh Bhugra, the author of Migration, Distress and Cultural Identity, suggests that "migration is a process of social change where an individual, alone or accompanied by others, because of one or more reasons of economic betterment, political upheaval, education or other purposes, leaves one geographical area for prolonged stay or permanent settlement in another geographical area" ${ }^{20}$. The process of migration involves the loss of social networks, isolation and alienation. These experiences lead to the processes of acculturation. In particular, "a series of factors in the environment combined with levels of stress, the ability to deal with stress, and the ability to root oneself according to one's personality traits, will produce either a sense of settling down or a sense of feeling isolated and alienated"21. When individuals migrate, they do not leave their beliefs or idioms of distress behind, no matter what the circumstances of their migration. However, the presentation of these beliefs and idioms of distress may vary across individuals, as do their memories and rebuilding processes.

19 J. C. Alexander, R. Eyerman, B. Giesen, N. J. Smelser, \& P. Sztompka, Cultural Trauma and Collective Identity, University of California Press: 2004.

20 D. Bhugra, Migration, distress and cultural identity, "British Medical Bulletin”, 69 (1): 2004, p. 129.

21 Ibid. 


\section{Losing and Rebuilding Memories of Mogadishu (and Themselves)}

Although people may experience a common war and resulting migration, individual stories can reveal the complexities of experiences. The individual stories that are told together demonstrate the rebuilding process and the various reflections along the way. Fowsia speaks to the experience of "up-rooting" and its effects across generations that she experienced:

That is a level of up-rooting for that generation for my grandma to come out of Somalia, of Africa and to come to north America, to me that was a major, sort of like a shift, it's like uprooting your settlement. So, that I remember you know wanting, because restarting the process and all that, wanting to make sure that they boarded their plane, they are coming. But then after hanging up the phone, thinking about Grandma Asha is on that plane and what that meant. I remember breaking down and crying in my own bedroom, thinking this is a shift in our settlement process, not only my sister and her children of two generations but this is like a third generation of an elderly person coming 22 .

Omar, a former government official who left Somalia in the early 1990s, recalls his experience, describing the patience required to deal with the whole process while also suggesting an active approach to change:

I am one of the people it affected the most, that the country took a long time to recover from the civil war. So, as I told you before, it was very hard for a person to have that patience. We have waited and we are still waiting, as a diaspora we are to blame because change does not just come, you have to take part in it ${ }^{23}$.

Coping is a complex and diverse process for different people, even in the face of similar contexts of war and migration. Dr. Hamdi Mohamed reflects that:

It's interesting. Different people have different ways of coping. My coping was not to think about Somalia. Once my family members left, I stopped thinking

22 A. Siad, Voice of Fowsia, op. cit.

23 Idem, Voice of Omar, Memories of Mogadishu, 2020, https://www.youtube.com/ watch? $v=$ mhjV82gQ0Zg\&t. 
about Somalia. Because we have lives to build. And all of us, many of us, had this hope at the back of our head. This...this is going to be a life temporarily outside of this country. We will eventually go back ${ }^{24}$.

In closing, Dr. Hersi Mohamed Eyow brings together the various themes explored throughout this paper through the following statement:

I remember a lady in a teashop came to me then she said to me "doctor do you know me?" I couldn't guess and she said that "you delivered me in Banadir hospital my first son." Ok, patients who are coming to know you they know you, but how many people you have given medical help, assistance or advice. That is why you feel good in yourself, somebody who you didn't remember that he is saying you are a medical doctor, you are my medical doctor, so and so. Then here... in Somali, it is called "I lost myself"; "wan is waayey", meaning I could not find a single person who recognized me, other than those who remembered me back home. So that is the difference, that is the memory I have there, but you don't have here ${ }^{25}$.

The interplay between what to remember and what to forget results in narratives that are constructed and expressed to fulfil psychological needs for the individual and socio-political functions for the groups and discourses that are influential in his or her life. Gemignani presents the notion that "memory is a key aspect of identity, the past is subject to practices of interpretation and power that shape the process and possibilities of identity construction at individual, political, and collective levels" ${ }^{26}$.Ultimately, Gemignani concludes with the notion of tensions between memories, namely that memory and remembering are cultural processes. These processes reproduce the tensions between what is believed to be unforgettable, and therefore what must be remembered versus what ought to be remembered. Despite these seemingly assigned remembering tasks, the individual may remember in other ways, and therein lies the tension.

24 Idem, Voice of Hamdi, op. cit.

25 Idem, Voice of Hersi, op. cit.

26 M. Gemignani, The past if past: The use of memories and self-healing narratives in refugees from the former Yugoslavia, "Journal of Refugee Studies", 24 (1): 2011, p. 141. 


\section{Conclusion}

As Lisa Ndejuru writes in A Modest Reconciliation, "owning and caring for stories calls for reorientation and recovery work among the many of us who have been led to believe such stories do not matter"27. Thus, it is crucial to understand the importance of storytelling in post-conflict societies and the ability that it has to harm or heal marginalized groups. At its core, Memories of Mogadishu seeks to build a collaborative storytelling platform for the Somali diaspora around the world to share their memories of Mogadishu with the hope of contributing to the reconstruction, reconciliation and healing of Somali.

Through the analysis of the nine interviews presented in our film, several important responses emerged in response to the research question: How does the Somali diaspora remember or reimagine Mogadishu? In describing Mogadishu relative to the period before the civil war, Mogadishu is remembered as an idealized cosmopolitan city filled with success, potential, opportunity, fun, and beauty in which the interviewees were living good lives. As interviewees recall the outbreak of war and their need to flee Mogadishu, the theme of personal and collective loss emerges in a way that also reflects a rupture and loss for the city of Mogadishu itself. A clear "before" and "after" period is presented, rooted in the trauma of war, migration, and layered displacement. A tension may exist between what ought to be remembered and what is actually remembered, especially as related to individual versus collective memories and healing processes. These are issues worth investigating in future research, especially through the lens of mediates memory work. It is also worth noting that the film premiered on YouTube on May 25, 2020, and at the time of writing this paper had over 6,000 views. Watching and sharing the film may be an additional means to remember, reimagine, and possibly reinforce the memories of Mogadishu.

In closing, Fowsia's words from the opening statement of this paper are brought back and read in light of the stories and memories of Mogadishu: "To me, memory is something that we live in all the time, live with, but the

27 L. Ndejuru, A Modest Reconciliation: Coming to Terms with Conflicted Stories through Oral History, Dialogue, and Playback Theatre in Montreal's Rwandan Canadian Community, [in] Forced Migration, Reconciliation, and Justice, Ed. M. Bradley, McGill Queens University Press: 2015. 
memory of a place. It fascinates me just how intertwined your thoughts, your dreams, your psyche is to a place that you might not have been for a long time"28. It appears that, among many who once called pre-war Mogadishu home, the revisiting of Mogadishu in their memory space is an ever present process that plays an important role in rebuilding Mogadishu, their communities, and their lives.

\section{References}

Alexander, J. C., Eyerman, R., Giesen, B., Smelser, N. J., \& Sztompka, P. (2004). Cultural Trauma and Collective Identity. University of California Press.

Bhugra, D. (2004). Migration, distress and cultural identity. British Medical Bulletin, 69(1), 129-141.

Gemignani, M. (2011). The past if past: The use of memories and self-healing narratives in refugees from the former Yugoslavia. Journal of Refugee Studies, 24 (1), 132-156.

Lohmeier, C., \& Pentzol, C. (2014). Making mediated memory work: CubanAmericans, Miami media and the doings of diaspora memories. Media, Culture \& Society, 36(6), 776-789.

Ndejuru, L. (2015). A Modest Reconciliation: Coming to Terms with Conflicted Stories through Oral History, Dialogue, and Playback Theatre in Montreal's Rwandan Canadian Community. In M. Bradley (Ed.), Forced Migration, Reconciliation, and Justice. McGill Queens University Press.

Ramzanali Fazel, S. (1994). Far From Mogadishu. Datanews.

Siad, A. (2020). Memories of Mogadishu. https://www.youtube.com/watch?v=mhjV82gQ0Zg\&t

28 A. Siad, Voice of Fowsia, op. cit. 